\title{
CARTA DE RECLAMAÇÃO, SEQUÊNCIA DIDÁTICA E ENSINO: TRIPÉ PARA 0 DESENVOLVIMENTO DO DISCURSO ARGUMENTATIVO INFANTIL
}

\author{
CARTA DE RECLAMACIÓN, SECUENCIA DIDÁCTICA Y ENSEÑANZA: TRÍPODE PARA EL DESARROLLO \\ DEL DISCURSO ARGUMENTATIVO INFANTIL
}

\section{LETTER OF COMPLAINT, DIDACTIC SEQUENCE AND LEARNING: TRIPOD FOR THE DEVELOPMENT OF CHILDREN'S ARGUMENTATIVE DISCOURSE}

\author{
Ana Paula Martins Alves ${ }^{1}$ \\ Mônica de Souza Serafim ${ }^{2}$ \\ Universidade Federal do Ceará
}

\begin{abstract}
RESUMO: Este texto tem por objetivo investigar o desenvolvimento do discurso argumentativo na escrita do gênero carta de reclamação de estudantes do $4^{\circ}$ ano do Ensino Fundamental de uma escola pública municipal brasileira, por meio do desenvolvimento de uma Sequência Didática. Para empreendermos este trabalho, baseamo-nos na concepção dialógica de linguagem de Bakthin (2003), na caracterização do gênero carta, com Barton \& Hall (2000) e Bazerman (2011) e nos estudos sobre a Sequência Didática, com Schneuwly e Dolz (2004). Os resultados mostraram, ao comparar-se as produções dos participantes, que a Sequência Didática é um dispositivo metodológico eficaz para um ensino sistemático e para um significativo desenvolvimento do discurso argumentativo.
\end{abstract}

PALAVRAS-CHAVE: carta de reclamação; sequência didática; discurso argumentativo infantil.

RESUMEN: Este trabajo tiene como objetivo investigar el desarrollo del discurso argumentativo en la redacción del género epistolar de reclamación de los estudiantes del cuarto año de primaria en una escuela pública de Brasil, a través del desarrollo de una secuencia didáctica. Para llevar a cabo este trabajo, nos basamos en la concepción dialógica del lenguaje de Bakhtin (2003), la caracterización del género la epistolar, con Barton \& Hall (2000) y Bazerman (2011) y estudios sobre la secuencia didáctica con Schneuwly y Dolz (2004). Los resultados mostraron, al comparar las producciones de los participantes, que la secuencia didáctica es una metodología eficaz para una enseñanza sistemática y para un desarrollo significativo del discurso argumentativo.

PALABRAS CLAVE: carta de reclamación; secuencia didáctica; discurso argumentativo infantil.

ABSTRACT: This paper aims to investigate the development of argumentative discourse in the writing of the letter-of-complaint genre by students in the 4th grade of elementary school in a Brazilian public school, through the development of a Didactic Sequence. To undertake this work, we relied on the dialogical conception of Bakhtin (1988), the letter-of-complaint genre by Barton \& Hall (2000) and Bazerman (2011), and Scheneuwly and Dolz's studies (2004) on didactic sequence. Results showed that, when the productions of the participants are compared, the Didactic Sequence is an effective methodology for a systematic teaching and for a significant development of argumentative discourse.

KEYWORDS: letter of complaint; didactic sequence; children's argumentative discourse.

\section{INTRODUÇÃO}

Estudos sobre a argumentação têm sido desenvolvidos desde os tempos de Aristóteles. Sob a concepção de que o sujeito falante apresenta um argumento como justificativa para determinada conclusão, a argumentação defendida pelos estudos retóricos pauta-se numa "verdade" do senso comum ou das leis gerais como princípios organizadores do mundo. Neste pensamento, o argumento se constitui por um fato que implica uma conclusão. No contexto deste trabalho, a argumentação tem um fim específico: apresentar argumentos sobre as reclamações dos principais problemas encontrados na escola.

Esse campo de investigação, o dos estudos da argumentação, ganhou particular relevância nas últimas décadas, destacando diferentes aspectos sobre o desenvolvimento do discurso argumentativo (SCHNEWLY; DOLZ, 2004).

\footnotetext{
${ }^{1}$ Mestra e Doutoranda em Linguística pela Universidade Federal do Ceará. Email: anarosa_teixeira@yahoo.com.br

${ }^{2}$ Professora do Curso de Letras e do Programa de Pós-Graduação em Linguística da Universidade Federal do Ceará. Email: mserafim15@gmail.com
} 
Sob o ponto de vista da argumentação na língua, em que o encadeamento argumentativo está ligado à estrutura linguística dos enunciados, a presente pesquisa teve por escopo investigar o desenvolvimento do discurso argumentativo na escrita do gênero carta de reclamação, a partir de uma sequência didática, de estudantes do $4^{\circ}$ ano do Ensino Fundamental de uma escola pública municipal brasileira.

Para apresentarmos os resultados desta pesquisa, organizamos este artigo da seguinte forma: a primeira seção é reservada para a caracterização do gênero carta de reclamação; a segunda apresenta considerações sobre a Sequência Didática, doravante SD; a terceira apresenta os procedimentos metodológicos de investigação; a quarta mostra a análise dos dados, seguida, pela última seção, que será a das considerações finais.

Na sequência, apresentamos considerações sobre o gênero carta de reclamação.

\section{CONSIDERAÇÕES SOBRE O GÊNERO CARTA DE RECLAMAÇÃO}

Vivemos em uma sociedade tecnologicamente moderna, em que a comunicação se dá de forma rápida e eficaz. Hoje, quando queremos dizer algo a alguém que está distante, escrevemos um e-mail, enviamos uma mensagem pelo celular, deixamos um recado no facebook, dentre outras formas de comunicação virtual. Todavia, durante muito tempo a comunicação entre os indivíduos se deu de forma muito mais lenta, se o diálogo não fosse face a face, a comunicação era estabelecida por meio de cartas, bilhetes, telegramas, entre outros meios bem diferentes dos meios atuais.

Nosso estudo objetivou analisar o desenvolvimento do discurso argumentativo em cartas de reclamação produzidas por alunos do ensino fundamental por meio do desenvolvimento de uma Sequência Didática. Os sujeitos participantes foram crianças com idade entre 9 a 12 anos e que, portanto, são usuários dessa modernização tecnológica dos meios de comunicação. Todavia, apesar da diversidade dos gêneros emergentes associados às tecnologias, muito provavelmente, as crianças dessa idade já tiveram contato com algum tipo de carta, seja no ambiente escolar, ou em casa, ou ainda em outros espaços. Isto porque, embora o gênero utilizado na pesquisa, a carta de reclamação, não seja utilizado com tanta frequência nos dias atuais, ainda é um gênero requerido em certas situações sociais. Contudo, embora atualmente não enviemos carta de reclamação via Correios, a escrita deste gênero, via email, é algo bastante comum atualmente. Os recursos tecnológicos disponíveis e as mídias atuais não modificaram este gênero; na verdade, o que se modificou foi o tipo de ferramenta de comunicação: da carta para o correio eletrônico.

Segundo Barton \& Hall (2000), a carta é uma das atividades de letramento mais difundidas na sociedade humana, atravessando os contextos mais formais e informais. Assim, diante das várias possibilidades de uso da carta, podemos afirmar que esta pode desempenhar diferentes papeis na interação social, podendo ser utilizada como meio de declaração de amor, amizade, meio de apresentação, agradecimento, ou ainda como veículo de reclamação.

Barton \& Hall (2000, p.1) ratificam que:

[…] carta, como um objeto de prática de letramento, é peculiarmente versátil e diversa. Como suporte de texto, a carta pode ser usada para mediar a interação humana. Através da carta, podemos narrar experiências, discutir pontos, descrever situações, oferecer explicações e outros. ${ }^{3}$

Bazerman (2011) destaca a natureza sociocomunicativa da carta. Para o autor, esse gênero textual apresenta uma comunicação direta entre duas partes (remetente e destinatário); além da confiabilidade conferida ao documento, ela possibilita a interlocução, ou seja, a troca, e permite a construção de relacionamentos (sociais) específicos em circunstâncias específicas. Assim, a carta, com sua comunicação direta entre dois indivíduos dentro de uma relação específica em circunstâncias específicas, pode ser um meio flexível no qual muitas funções, relações e práticas institucionais podem se desenvolver.

Ao pesquisar sobre a origem dos gêneros, Bazerman (2011) desenvolve um ensaio sobre as cartas como base social de um grande número de gêneros escritos de nosso cotidiano. Segundo o autor, a carta serviu de

${ }_{3}^{3}$ Tradução nossa. 
tipificação dos artigos científicos, dos relatórios de acionistas, das atas de condomínio, dos cheques, das faturas, das cartas de créditos e das reportagens, por exemplo. Assim, tendo em vista as várias possibilidades de uso das cartas em distintos campos de atividade, tais como a propaganda, a carta pessoal, entre outros, notamos o papel que este gênero textual representa na interação social.

Ao relacionar a carta a outros gêneros, Marcuschi (2010) situa a carta dentro de um contínuo existente entre alguns gêneros tradicionais na fala e na escrita. Ao mostrar esse contínuo, o teórico fala das noções de comunicação síncrona, comunicação que se dá no tempo real, e comunicação assíncrona, a comunicação escrita que, no geral, apresenta uma defasagem no tempo.

A carta é um gênero que apresenta uma estrutura composicional bastante tipificada e cristalizada em nossa sociedade. De um modo geral, quando falamos em escrever uma carta, facilmente nos vem à memória como esse texto deve ser configurado, ou seja, sabemos que o texto terá uma configuração específica, como uma data e um local, que escreveremos direcionado a alguém e que, por isso, é necessário um destinatário, que após o desenvolvimento do conteúdo do texto, irá se despedir e assinar.

Todavia, em consonância com Barton \& Hall (2000), a carta pode assumir várias possibilidades de uso, podendo ser utilizada como meio de declaração de amor, amizade, meio de apresentação, agradecimento ou ainda como veículo de reclamação. Assim, em cada contexto de uso, embora a carta assuma uma tipificação geral, esta adaptar-se-á ao contexto e ao propósito comunicativo.

Tendo em vista que nosso estudo trata do discurso argumentativo em cartas de reclamação, faz-se necessário discutirmos a respeito dos aspectos estruturais desse gênero específico.

Ao debater a respeito da configuração sequencial típica do gênero carta, Gomes (2002, p. 37) descreve as funções constitutivas do gênero epistolar, da seguinte forma:

- $\quad$ local e data - têm o papel de situar o destinatário no processo de produção da informação. É uma forma de recuperar a situação natural de diálogo face a face;

- a saudação inicial - como parte facultativa, tem em geral ou uma função fática ou complementar ao 'pacto';

- o corpo - tem a função de realizar o(s) propósito(s) principal(is) do autor da carta;

- a saudação final - também tem uma função fática, porém, em função do propósito, pode assumir alguma função argumentativa;

- a assinatura - tem o papel de identificar o remetente com a possibilidade de confirmar o grau de aproximação apresentado no início;

- $\quad$ pós-escrito - tem a função de preencher as lacunas informacionais do corpo ou de enfatizar $\mathrm{o}(\mathrm{s})$ propósito(s).

Notamos que Gomes (2002) relaciona cada parte da carta às funções de linguagem propostas por Roman Jakobson. Contudo, gostaríamos de destacar a importância que o estudioso dá à saudação inicial, ou seja, às formas de tratamento utilizadas junto ao vocativo. Para Gomes (2002), a forma de tratamento utilizada junto ao vocativo marca o grau de formalidade entre os atores, podendo indicar um grande distanciamento (Prezado Senhor) ou um pequeno distanciamento (Querido Amigo). Consideramos, pois, que o vocativo exerce um importante papel, uma vez que por meio dele podemos identificar a natureza do relacionamento entre os interlocutores.

Dissertando sobre a estrutura composicional do gênero textual carta, Silva (2002) afirma que essa é composta por Abertura do evento, Corpo do texto, Encerramento do evento e Post scriptum (facultativo).

A abertura do evento é o momento em que se estabelece o contato e a interlocução com o destinatário. Nela devem constar o local, a data e o vocativo. É na abertura que verificamos a natureza do relacionamento dos interlocutores, a finalidade que cumpre a interação em curso e, sobretudo, o caráter dialógico desse gênero. No corpo da carta, há o desenvolvimento do objeto do discurso, ou seja, é nesse espaço que o propósito comunicativo é explicitado. No encerramento do evento, temos a conclusão, espaço em que deve haver a saudação final e a assinatura daquele que escreve.

No que diz respeito à carta de reclamação, Barbosa (2005), investigando sobre a distinção entre cartas, solicitação e cartas de reclamação, define que a carta de reclamação possui os seguintes elementos em sua Forum linguistic., Florianópolis, v.11, n.4, p.385-402, out./dez.2014. 
organização: data, identificação do destinatário e do cargo que ocupa, identificação do motivo da carta e do remetente, explicações sobre o pedido, relatos, argumentações, que sustentem o pedido, formas de despedidas típicas, por último nome e/ou assinatura do remetente.

Aproximando-se um pouco mais do nosso contexto de pesquisa, o estudo de Melo (2009), sobre a apropriação do gênero carta de reclamação por alunos da educação de jovens e adultos, nos oferece um relevante modelo de carta de reclamação. O modelo proposto por Melo (2009, p. 74) apresenta as seguintes categorias:

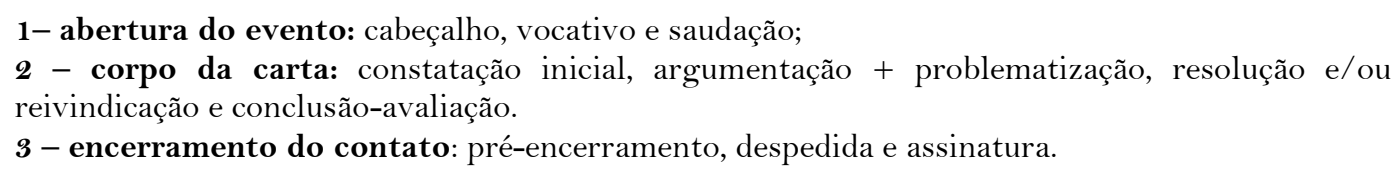

O modelo de carta de reclamação apresentada por Barbosa (2005) é bastante interessante, principalmente no que diz respeito às explicações sobre o pedido, relatos e argumentações. Contudo, visto que nosso estudo se desenvolveu por meio da produção de cartas por crianças, o modelo proposto por Melo (2009) se torna mais concreto para os alunos dos anos iniciais do ensino fundamental. Todavia, tendo em vista o objetivo da pesquisa, investigar o desenvolvimento do discurso argumentativo de crianças na produção de carta de reclamação, sentimos a necessidade de definir um modelo próprio de análise, não menos relevante, porém um pouco mais direto.

Com isso, como estrutura composicional do gênero carta, adotamos as seguintes categorias de análise:

1. abertura do evento: cabeçalho, vocativo e saudação;

2. corpo da carta: identificação do motivo da carta, apresentação da reclamação, argumentos e conclusão.

3. encerramento do evento: despedida e assinatura.

Além das categorias apresentadas acima, destacamos a disposição tipográfica como uma das categorias, também, relevantes de serem observadas nas cartas de reclamação. De acordo com Boisssinot (1992), a disposição tipográfica está associada à distribuição formal de blocos de informações no texto, considerada apenas na dimensão dos parágrafos. No entanto, consoante ao estudo de Melo (2009), acreditamos que a disposição tipográfica diz respeito à disposição espacial adequada dos elementos do texto, tais como cabeçalho, vocativo, saudação, despedida e assinatura, uma vez que estes elementos assumem importante papel no gênero em estudo.

Embora o gênero carta exista desde a antiguidade e apresente uma forma facilmente identificável e fortemente tipificada, percebemos que ainda há uma carência de estudos que apresentam este gênero na perspectiva de sua apropriação em contexto de ensino. Portanto, destacamos a real necessidade de ensino do gênero carta de reclamação desde seus aspectos estruturais e aspectos dialógicos, tão necessários numa sociedade persuasiva como a nossa.

$\mathrm{O}$ aspecto argumentativo emerge, no gênero carta de reclamação, a partir dos argumentos que serão colocados pelos alunos e que levarão o texto à progressão da informação.

Segundo Koch (2003), um texto compõe-se de segmentos tópicos, relacionados ao tópico discursivo ou tema geral. Para Jubran et al (1992), o tópico discursivo é "aquilo acerca de que se está falando". Os autores situam o tópico como uma questão de conteúdo informativo e, do mesmo modo, assinalam também que se trata de um processo essencialmente colaborativo, uma vez que o tópico é construído no ato interacional, com a participação dos envolvidos no evento.

Jubran et al. (1992) reforçam que, como o tópico é uma construção conjunta, no processo de trocas verbais estão envolvidas circunstâncias como o conhecimento entre os interlocutores, a visão de mundo, o background de cada um em relação aos que falam, bem como suas proposições.

Os autores postulam, ainda, que um texto é constituído de fragmentos recobertos por um mesmo tópico e que a descontinuidade do segmento tópico constituem dois grandes grupos: processos de inserção e processos de reconstrução. 
As inserções são definidas como segmentos discursivos de extensão variável que provocam uma espécie de suspensão temporária do tópico em curso, estas desempenham a funções interativas como ilustrar, explicar, atenuar, introduzir avaliações ou atitudes do locutor etc. Já a reconstrução é definida como a re-elaboração da sequência discursiva, tendo a função de formular melhor ou reformular um segmento maior ou menor do texto já produzido, com o objetivo de sanar problemas.

No que diz respeito à mudança tópica, Jubran et al (1992) afirmam que esta é ocasionada pela continuidade ou descontinuidade tópica, e pode ocorrer de três formas: a) introdução de um tópico após o encerramento/esgotamento do anterior; b) passagem gradativa de um foco de relevância para outro; e c) introdução de um tópico por abandono de outro, havendo um corte brusco do tópico que estava em pauta.

Uma vez que utilizamos a carta de reclamação como gênero profícuo para o desenvolvimento do discurso argumentativo infantil, vale destacar o estudo de Leitão (2011) sobre a argumentação na escola. A autora defende que para trazer a argumentação para dentro da sala de aula é preciso ultrapassar a restrição sofrida pelos temas curriculares e propor temas mais polêmicos, socialmente percebidos. Segundo a autora, a argumentação cotidiana é caracterizada por um tema polêmico, não possível de prever uma conclusão final e como um espaço em que os envolvidos na argumentação podem ser influenciados e mudar de ponto de vista.

Os alunos participantes da pesquisa foram solicitados a produzir cartas de reclamação para a direção da escola expressando suas reclamações a respeito dos aspectos escolares merecedores de intervenção. O tema das cartas surgiu após a observação do contexto escolar e conversas com os alunos e professores.

Assim, para analisarmos as cartas produzidas pelos participantes, elegemos duas categorias que potencialmente nos conduzirão a uma melhor compreensão do desenvolvimento do tema nas produções dos estudantes. Destarte, observaremos a questão da pertinência ao tema, ou seja, quanto o aluno consegue se engajar ou não ao tema proposto.

Para analisarmos como os alunos desenvolveram o discurso argumentativo por meio do gênero carta de reclamação, a seguir, teceremos considerações sobre a Sequência Didática.

\section{O ENSINO DE GÊNEROS TEXTUAIS E A SEQUÊNCIA DIDÁTICA}

Por meio de discussões acerca do ensino da linguagem na perspectiva do letramento, diversos estudiosos (FERRO, 1997; SILVA, 2002; SCHNEUWLY; DOLZ, 2004; LIMA, 2006) têm defendido o trabalho com gêneros textuais no âmbito escolar. Tendo em vista que "a condição de sujeito letrado se constrói nas experiências culturais com práticas de leitura e escrita que os indivíduos têm oportunidade de viver, mesmo antes de começar sua educação formal” (MORAIS; ALBUQUERQUE, 2004, p. 69), o trabalho com gêneros textuais em sala de aula tornou-se, nas últimas décadas, bastante relevante no ensino de língua materna, uma vez que possibilita o educando a lidar com a língua em diversos usos do cotidiano.

De acordo com Bakhtin (2003), os gêneros discursivos se definem como relativamente estáveis, veiculados às diferentes áreas de atividade humana e caracterizados por conteúdo temático, construção composicional e estilo. Desse modo, as necessidades da temática, o conjunto dos participantes e a vontade enunciativa ou intenção do locutor determinam a escolha de um gênero numa situação de interação de linguagem.

Segundo Kress (1989, p. 19 apud BALOCCO, 2005, p. 65),

Os gêneros são tipo de texto que codificam os traços característicos e as estruturas dos eventos sociais, bem como os propósitos dos participantes discursivos envolvidos naqueles eventos. Assim, os gêneros textuais (orais e escritos) constituem um 'inventário' dos eventos sociais de determinada instituição, ao expressarem aspectos convencionais daquelas práticas sociais, com diferentes graus de ritualização.

Por meio dos gêneros, reconhecemos características da situação social e institucional, estes nos ajudam a navegar em mundos complexos de comunicação, nos quais percebemos as atividades e os papeis disponíveis aos interlocutores, assim como ideologias, ideias e conteúdos (BAZERMAN, 2011).

Numa sociedade letrada como a nossa, convivemos diariamente com uma grande diversidade de gêneros e, por consequência, constantemente nos é exigida uma interação com esses. No entanto, nessa variedade de gêneros textuais, uns são mais semelhantes a outros, enquanto que outros diferenciam-se mais entre si. Isso Forum linguistic., Florianópolis, v.11, n.4, p.385-402, out./dez.2014. 
se dá devido ao fato de os gêneros não estarem soltos numa realidade sócio-histórica, pelo contrário, a própria vida social e a atuação dos sujeitos são encadeadas por uma série de textos com características típicas determinadas socialmente, mas que permitem mudanças e inter-relações. Com isso, Marcuschi (2011, p. 13) afirma que "dominar gêneros é agir politicamente", uma vez que é por meio dos gêneros que o engajamento pessoal na sociedade se efetiva.

Nesse contexto, Schneuwly \& Dolz (2004) defendem que o gênero é um meio de articulação entre as práticas sociais e os objetos escolares e que, portanto, é imprescindível o ensino de produção e compreensão de textos orais e escritos.

Segundo Schneuwly (2004, p. 27), “o gênero é um 'instrumento”. Nessa acepção, ele é visto como uma ferramenta importante e necessária para o desenvolvimento de diversas atividades orais ou escritas. Sendo considerado como um instrumento semiótico e complexo, os gêneros são mediadores das ações discursivas que acontecem entre sujeitos, ou seja, são mega-instrumentos que medeiam, dão forma e viabilizam a materialização de uma atividade de linguagem.

Todavia, o professor deve estar atento para não repetir velhas práticas, ou seja, não ensinar o gênero visando apenas sua classificação, mas, sobretudo, o ensino do gênero deve-se pautar na compreensão da sua função social. Marcuschi (2011, p. 11) reforça que, “[ [...] não se ensina um gênero como tal e sim se trabalha com a compreensão de seu funcionamento na sociedade e na sua relação com os indivíduos situados naquela cultura e suas instituições".

Destarte, nessa perspectiva de gênero e concebendo o texto numa acepção sócio-interacionista, estudiosos como Bronckart (1991) e Schneuwly \& Dolz (2004) propõem uma abordagem de ensino centrada na diversificação de textos e nas relações que estes mantêm com seu contexto de produção, enfatizando os aspectos sociais e históricos.

Neste trabalho, utilizaremos o termo gênero discursivo, uma vez que entendemos que o acesso à diversidade de gêneros e o estudo deles devem nortear o processo de ensino e aprendizagem da língua, o qual deve ter como objetivo principal desenvolver a competência discursiva de seus usuários. Sabemos que, no ambiente escolar, diversas ocasiões de escrita e de fala são oferecidas aos alunos, sem que estas sejam necessariamente o objeto de um ensino sistemático. No entanto, Schneuwly \& Dolz (2004) defendem que para os alunos se apropriem de noções, de técnicas e de instrumentos necessários ao desenvolvimento de suas capacidades de expressão oral e escrita, em situações diversas de comunicação, é preciso criar contextos de produção precisos e efetuar atividades ou exercícios múltiplos e variados. Não obstante, o trabalho pedagógico de ensino da linguagem por meio de gêneros deve se traduzir como um acervo de ações oriundo do:

[...] interesse real na vida dos alunos e cuja realização envolve o uso da escrita, isto é, a leitura de textos que, de fato, circulam na sociedade e a produção de textos que serão realmente lidos, em um trabalho coletivo de alunos e professor, cada um segundo sua capacidade. (KLEIMAN, 2000, p. 238).

A escola, como uma das agências de letramento, deve fomentar as práticas sociais de uso da linguagem, uma vez que trabalhar com gêneros no âmbito escolar é trazer o discurso da sociedade para dentro da sala de aula, e, consequentemente, é compreender a língua em funcionamento.

Nessa perspectiva, Schneuwly \& Dolz (2004) apresentam a Sequência Didática (SD) como um procedimento que torna possível o alcance de tais objetivos. Para os autores (2004, p. 97), “uma ‘sequência didática’ é um conjunto de atividades escolares organizadas, de maneira sistemática, em torno de um gênero textual oral ou escrito".

Os autores destacam que a finalidade principal de uma SD é ajudar o aluno a dominar melhor um gênero textual, permitindo-lhe o uso de maneira mais adequada à situação comunicativa. Para tanto, o trabalho escolar a ser realizado com a SD focará aqueles gêneros que o aluno não domina ou então o faz de maneira insuficiente, focará aqueles gêneros que são mais dificilmente acessíveis, no entanto, gêneros públicos e não privados. 
Schneuwly \& Dolz (2004) descrevem uma estrutura de base de uma SD, a qual é representada pelo esquema a seguir:
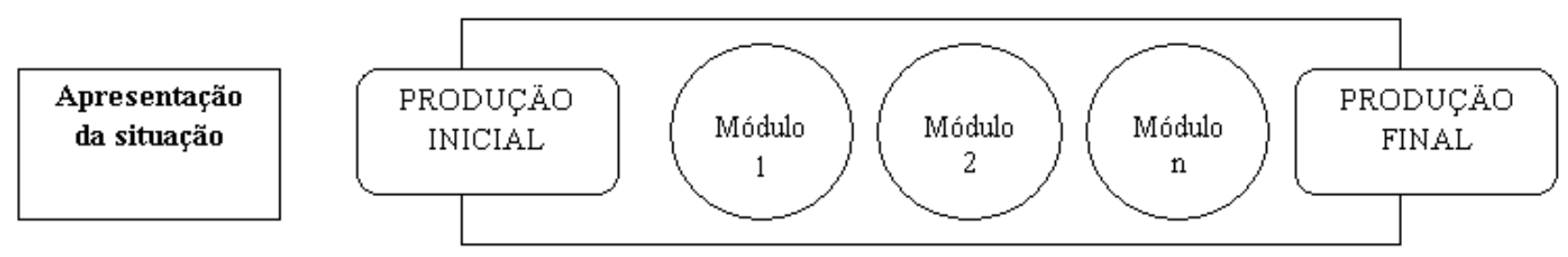

Figura 1: Esquema da Sequência Didática

Fonte: Schnewly \& Dolz (2004, p.98)

Segundo os autores, para iniciar uma SD, primeiramente, é necessário fazer a apresentação da situação, ou seja, expor aos alunos o projeto de comunicação que será realizado na produção final. É o momento de preparação para a produção inicial, portanto, é nessa etapa que a turma constrói uma representação da situação de comunicação e da atividade de linguagem a ser executada. Embora esta seja a fase introdutória da sequência, segundo Schneuwly \& Dolz (2004), é um momento crucial e difícil, pois este compreende duas dimensões importantes para o andamento da SD: a) a definição do problema de comunicação e b) a preparação dos conteúdos.

De acordo com os autores, o problema de comunicação deve ser exposto aos alunos de maneira bem explícita para que eles compreendam da melhor forma a situação de comunicação na qual devem agir. Para isso, na apresentação da situação, devem ser expostas as respostas para as seguintes perguntas:

- Qual gênero será abordado?

- A quem se destina a produção?

- Que forma assumirá a produção?

- Quem participará da produção?

A outra dimensão citada pelos autores é a preparação dos conteúdos que serão trabalhados. Na apresentação da situação, é necessário que os alunos percebam a importância dos conteúdos que irão trabalhar.

A apresentação da situação permite, pois, que os alunos tenham informações necessárias para que conheçam o projeto comunicativo do qual irão participar.

Após a apresentação da situação, parte-se para a produção inicial. Nesse momento, os alunos procuram elaborar um primeiro texto a partir de seus conhecimentos reais. Os autores salientam, contudo, que se o problema de comunicação for bem definido e os conteúdos bem preparados na apresentação da situação, até os alunos mais "fracos" serão capazes de produzir um texto que corresponda à situação dada. A partir da produção inicial dos alunos, o professor terá subsídios para definir o caminho que o aluno ainda precisa percorrer e com isso desenvolver as demais etapas necessárias para a produção final.

A etapa seguinte à produção inicial são os módulos. Este é o momento de trabalhar os problemas apontados na produção inicial. Aqui serão trabalhadas as especificidades para se chegar ao todo. Schneuwly \& Dolz (2004) esclarecem que o movimento da SD vai do complexo para o simples, ou seja, da produção inicial aos módulos, cada um trabalhando uma ou outra capacidade necessária ao domínio de um gênero, para então, ao final, retornar ao complexo novamente, a produção final.

Por fim, temos a produção final, momento em que o aluno irá colocar em prática as noções e os instrumentos elaborados separadamente nos módulos. É nessa etapa que serão verificados se os objetivos iniciais foram alcançados ou não.

Schneuwly \& Dolz (2004) afirmam que no processo de ensino e aprendizagem deve ser deixado um espaço para as atividades mais informais e menos exigentes em termos de tempo. As sequências devem funcionar como exemplos à disposição dos professores. 
Em síntese, tendo em vista o ensino e a aprendizagem de textos no contexto escolar, nossa pesquisa assume em seu arcabouço teórico: a) uma concepção de linguagem considerada em sua dimensão discursiva e sóciohistórica; b) uma concepção de ensino e aprendizagem que se realiza em atividades sociais mediadas pela linguagem com a participação do sujeito como agente; c) uma concepção de gênero, em sua acepção bakthiniana, como enunciados relativamente estáveis e tipicamente determinados, bem como meio de articulação entre as práticas sociais e os objetos escolares (SCHNEUWLY; DOLZ, 2004); e d) uma concepção argumentativa baseada nas escolhas linguísticas do falante (DUCROT, 1990).

A intervenção pretendida nesta pesquisa baseou-se na noção de SD definida por Schneuwly \& Dolz (2004), em que, a partir de uma série de encontros planejados e realizados com o grupo participante, intencionamos a produção de uma carta de reclamação. Contudo, destacamos que o foco da nossa análise está no discurso argumentativo utilizado pelos alunos nas cartas. Todavia, reconhecemos a eficácia da SD para a construção do discurso argumentativo dos alunos nesse gênero específico.

Nesse contexto, compreendemos que os gêneros textuais se apresentam como instrumentos eficazes no processo de apropriação da escrita e, consequentemente, na apropriação do discurso argumentativo escrito. Entendemos, no entanto, que essa apropriação depende de um planejamento adequado e comprometido com a aprendizagem significativa dos alunos.

\section{A PRODUÇÃO DA CARTA DE RECLAMAÇÃO}

Nosso corpus é composto por quarenta cartas de reclamação produzidas por dez alunos do $4^{\circ}$ ano do ensino fundamental de uma escola pública municipal brasileira.

Os dados analisados neste estudo foram coletados em três etapas. Na primeira etapa, foi composta por dois momentos. No primeiro momento, fomos à escola para um primeiro contato com a direção. Na ocasião, conversamos sobre o propósito da pesquisa e decidimos qual turma faria parte do estudo. No segundo momento, conversamos com a professora da turma escolhida e decidimos como ocorreriam as intervenções nas aulas.

A segunda etapa foi constituída por observações das aulas. Nesse momento, houve o primeiro contato da pesquisadora com a turma participante e procuramos observar como se configurava a rotina da turma, assim como o comportamento e o envolvimento dos alunos nas atividades propostas.

Por fim, na terceira etapa, desenvolvemos uma sequência didática com sete encontros de 100 minutos cada um (duas aulas de 50 minutos geminadas), os quais ocorreram nos meses de setembro e outubro de 2012. Nessa etapa da pesquisa, atuamos como pesquisador e professor durante o desenvolvimento de todos os passos da Sequência Didática.

Os encontros foram semanais (dois encontros por semana) e realizados no espaço reservado às aulas de Língua Portuguesa. A professora da turma esteve presente em todas as aulas ministradas.

Os dados foram coletados no mês de comemoração de aniversário de 10 anos da escola participante da pesquisa. Na ocasião, a escola estava desenvolvendo diversas atividades a fim de envolver a comunidade escolar (alunos, pais, professores, coordenadores e demais funcionários) na comemoração.

De um modo geral, a turma foi participativa. Os alunos sempre eram receptivos a solicitações e comandos feitos ao longo do desenvolvimento da SD e, na maioria dos casos, percebia-se uma preocupação em tentar fazer o melhor.

Nosso estudo partiu do pressuposto de que os gêneros são tipos de enunciados relativamente estáveis e convencionais, veiculados nas diferentes áreas de atividade humana, que se estabilizam por meio das categorias que lhes são prototípicas. Segundo Schneuwly \& Dolz (2004), os gêneros são mega-instrumentos que podem ser utilizados como meio de articulação entre as práticas sociais e os objetos de aprendizagem.

No entanto, de acordo com os autores supracitados, para que os alunos se apropriem de noções, de técnicas e de instrumentos necessários ao desenvolvimento de suas capacidades de expressão oral e escrita, é preciso 
criar contextos de produção precisos e efetuar atividades ou exercícios múltiplos e variados. Para tanto, os autores apresentam a Sequência Didática (SD) como um procedimento capaz de tornar possível o alcance de tais objetivos.

O modelo de carta de reclamação proposto para nossa análise é constituída por três grandes categorias: abertura do evento, corpo da carta e encerramento do evento.

As três categorias constituintes da carta de reclamação, adotada por nós, se desdobram nos seguintes elementos: cabeçalho, vocativo e saudação (GOMES, 2002; SILVA, 2002; MELO, 2009); identificação do motivo da carta, apresentação da reclamação (BARBOSA, 2005), argumentos (BARBOSA, 2005; MELO, 2009), conclusão (SILVA, 2002; BARBOSA, 2005; MELO, 2009), despedida e assinatura (GOMES, 2002; SILVA, 2002; BARBOSA, 2005; MELO, 2009).

Acrescentamos às categorias de análise dos aspectos estruturais da carta de reclamação, a categoria disposição tipográfica, visto que esta, segundo Boissinot (1992), está associada à distribuição formal de blocos de informações no texto. Salientamos, no entanto, que consideramos como disposição tipográfica a disposição espacial adequada dos seguintes elementos: cabeçalho, vocativo, saudação, despedida e assinatura, pois percebemos a importância destes para a estabilização do gênero em estudo.

A carta de reclamação é caracterizada pelas categorias presentes em sua estrutura, como: identificação do motivo da carta, apresentação da reclamação, dos argumentos e da conclusão. É nestas categorias que encontramos as marcas de argumentação, cuja discussão será feita a partir da próxima seção.

Partimos da hipótese de que após o desenvolvimento da SD, verificar-se-ia, nas produções dos sujeitos da pesquisa, um considerável progresso no conhecimento dos elementos estruturais do gênero carta de reclamação.

O gráfico 1, a seguir, demonstra a quantidade dos elementos estruturais do gênero carta de reclamação utilizados pelo grupo de alunos participantes.

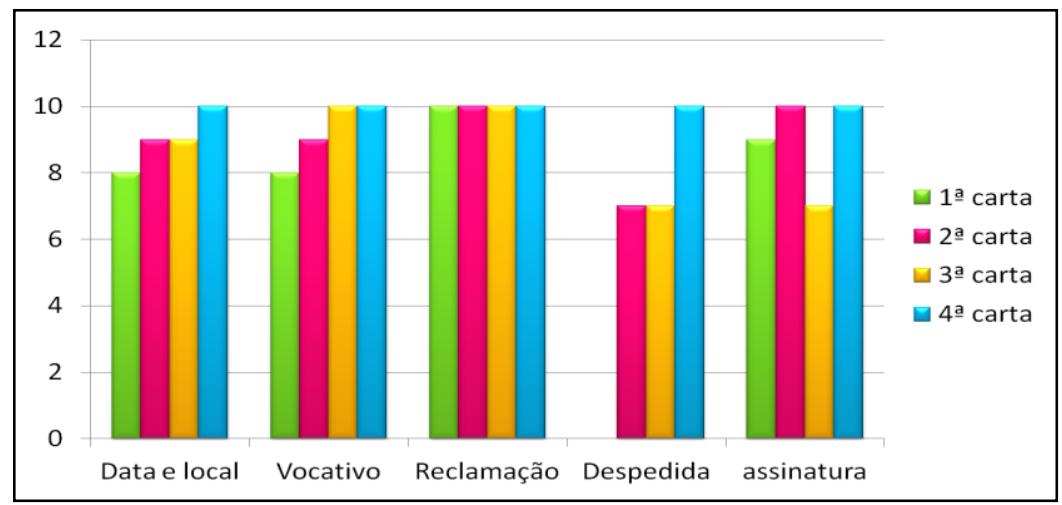

Gráfico 1: Frequência de utilização dos elementos estruturais do gênero carta de reclamação

Deste gráfico, podemos observar que:

a) De uma produção para outra houve um significativo acréscimo no uso dos elementos estruturais do gênero carta de reclamação;

b) Na abertura do evento, percebemos uma crescente utilização da data, do local e do vocativo;

c) No corpo da carta, notamos a presença da argumentação desde a primeira produção;

d) No encerramento do evento, verificamos uma diferença considerável, em relação à despedida, entre a primeira e a última produção;

Os dados demonstram que houve um acréscimo significativo no uso dos elementos estruturais do gênero carta de reclamação. Isso evidencia que as categorias eleitas neste estudo como constituintes da carta de reclamação podem ter sua aprendizagem facilitada por meio do ensino sistemático direcionado para tal fim.

Ao observarmos o gráfico 01, percebemos que $80 \%$ dos alunos escreveram a data e o local e $90 \%$ escreveram a assinatura na primeira produção, ao passo que $100 \%$ dos alunos escreveram a data, o local e a assinatura Forum linguistic., Florianópolis, v.11, n.4, p.385-402, out./dez.2014. 
na última produção. Acreditamos que a porcentagem na produção inicial se deu devido ao fato de termos trabalhado, de forma breve, o gênero carta no momento da apresentação da situação de comunicação, o que levou os alunos a resgatarem o conhecimento prévio da estrutura da carta.

A presença de tais aspectos, de forma parcial na produção inicial e total na produção final, nos dá a ideia de que tais cartas estão situadas no tempo e no espaço, bem como possuem um autor (BARTON; HALL, 2000), além do mais percebemos um início e um fim do evento comunicativo.

No que diz respeito ao uso do vocativo, percebemos a utilização deste desde a primeira carta. Entre os vocativos citados nas cartas, temos: Querida diretora, Caro diretor; Prezada diretora e Senhora diretora.

$\mathrm{Na}$ primeira produção, 70\% dos alunos utilizaram “querida diretora”, e apenas 10\% na terceira e quarta produção. Considerando as características do gênero carta de reclamação, destacamos a inadequação do termo "querida diretora”, uma vez que, neste gênero, espera-se uma linguagem mais formal e uma relação de distanciamento com o interlocutor. No entanto, acreditamos que essa ocorrência na primeira produção se deu devido ao fato dos sujeitos da pesquisa serem crianças e, por isso, expressam sua afetividade mais facilmente, bem como devido ao fato de os alunos não terem contato com esse modelo de carta e, consequentemente, desconhecerem a formalidade exigida pelo gênero.

Ainda em relação ao vocativo, salientamos que na terceira produção tivemos a ocorrência do termo "Prezada Diretora" em todos os textos. Tal fato, acreditamos, ocorre porque, nesse texto, os alunos fizeram uma reescrita da carta de um dos alunos e, na carta modelo, o redator utilizou "Prezada Diretora". No entanto, é oportuno destacar a crescente adequação da utilização do vocativo nas produções: apenas $10 \%$ das produções utilizaram o termo "querida diretora”, ao passo que $70 \%$ utilizaram "senhora diretora" e $20 \%$ "prezada diretora”.

Com relação ao corpo da carta, os alunos, de um modo geral, apresentaram ao menos uma reclamação; contudo, demonstraram dificuldades na apresentação da reclamação e dos argumentos. As categorias que constituem o corpo da carta são de grande importância para o propósito do gênero, visto que é exatamente no corpo da carta que o propósito comunicativo é explicitado, bem como a argumentação é constituída.

Sobre as reclamações mais frequentes nas produções, percebemos que a principal reclamação dos alunos é a respeito do banheiro. Segundo os relatos, esses são sujos, sem água e sem material necessário para uma boa higienização, tais como, papel higiênico, água e sabonete. Em relação à sala de aula, espaço em que os alunos passam a maior parte do tempo, destacam que são quentes, sujas, barulhentas (devido a uma avenida ao lado da escola) e tem uma aparência desagradável por conta das paredes riscadas. A terceira reclamação mais recorrente nas cartas foi com relação à merenda escolar. Os alunos reclamam da falta de qualidade na merenda, sendo esta muitas vezes sem sal e mal preparada.

Vale ressaltar que todas as reclamações foram iniciativas dos próprios alunos. Ao produzir a carta, cada aluno deveria escolher sua(s) própria(s) reclamação(ões) sem interferência da professora da turma ou da pesquisadora. Assim, afirmamos que as reclamações originaram-se no cotidiano dos alunos.

No que tange ao encerramento do evento comunicativo, percebemos que a despedida não tem nenhuma ocorrência na primeira produção, no entanto apresenta $100 \%$ de ocorrência na última produção. Isso evidencia o significativo progresso dos alunos em relação a este elemento constitutivo da carta. Porém, assim como o vocativo, é interessante destacar a adequação do termo utilizado na despedida.

Entre os termos mais recorrentes temos: beijos, atenciosamente; sem mais; abraços e obrigado, como nos mostra o gráfico a seguir: 


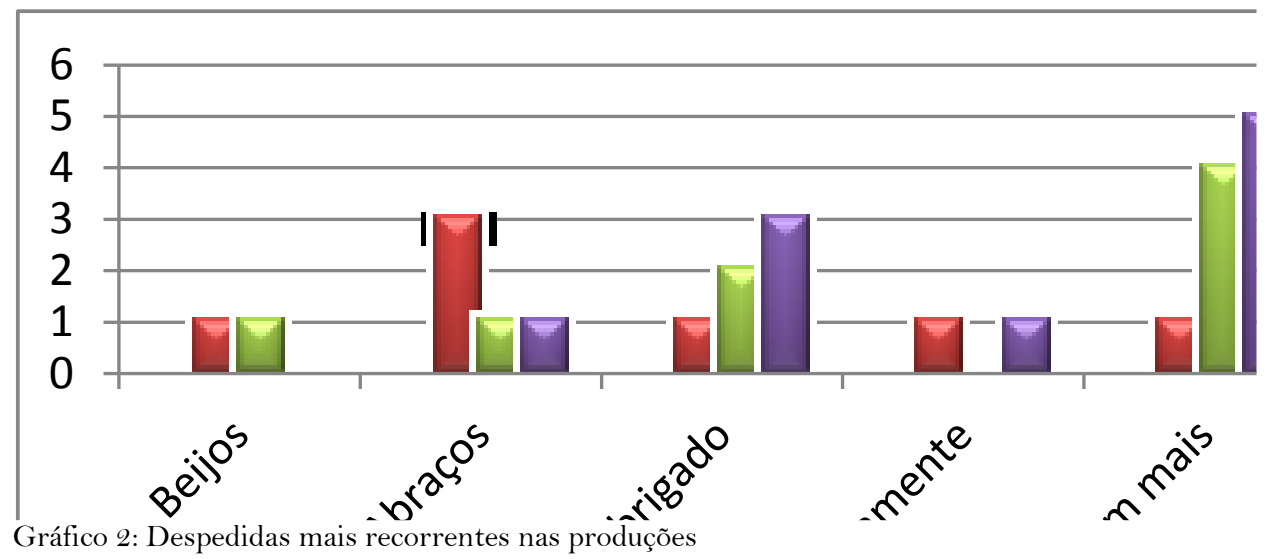

O gráfico nos revela uma pequena porcentagem de utilização dos termos "beijos" e "abraços" na segunda e terceira produção. No entanto, notamos que $10 \%$ dos alunos utilizaram "obrigado" na segunda produção, $20 \%$ na terceira e $30 \%$ na quarta produção. Isso demonstra que ainda houve um número considerável de alunos que utilizaram inadequadamente a despedida, mesmo depois das atividades desenvolvidas ao longo da sequência didática. Contudo, vale salientar que $40 \%$ dos alunos conseguiram perceber a adequação dos termos utilizados na despedida em suas produções a partir da terceira produção e $50 \%$ permaneceram com tal adequação na quarta produção.

Destarte, tendo por base o modelo tomado como categoria de análise, apresentamos as produções do aluno A5 (exemplos (1a), (1b), (1c) e (1d)), e analisamos a apropriação dos elementos prototípicos do gênero carta de reclamação ao longo do desenvolvimento da SD.

$(\mathbf{1})^{4}$ Reclamação

$\begin{array}{ll}\text { - } & \text { O banhero seta muio sujo é fedorento } \\ \text { - } & \text { O retreio senta muio violento } \\ \text { - } & \text { Aorfavor podem ageita } i \text { so } \\ \text { - } & \text { Sacadicia setades coidada } \\ & \text { Salan quebrada }\end{array}$

A5 (Produção Inicial)

(1b) $)^{5}$ Destinatário diretora Data 19/09/2012

Querida diretora esae uma cartade reclamação. Ubanheiro estamuito cusjo e fedoreto é esta quebrado é amerenda é ruin é muito sujo e asalade aulaesta comuito boraquo final decarta

\section{A5 (2 $\mathbf{2}^{\mathrm{a}}$ Produção)}

(1c) Prezada diretora Queridadiretora mel nome e A5 sol do $4^{\circ}$ ano B esa cartadereclamação.

O banheiro do colégio estão rabiscado não tem espelho e a maioria dos vasos sanitários estão quebrados as luz não funciona, e não tem papell higiênico no banheiro dos meninos.

Origada pela reforma queridadiretora ciacinomra refola o banheiro dos meninos a escolaficaria melho.

\section{Nome: A5 (3ª produção) $\quad$ Fortaleza, o1 de outubro de 2012}

\footnotetext{
${ }^{4}$ Reclamação - o banheiro está muito sujo, é fedorento. O recreio esta muito violento. Por favor, podem ajeitar isso. A polícia está descuidada. As cadeiras estão quebradas.

${ }^{5}$ Querida diretora essa é uma carta de reclamação. O banheiro está muito sujo e fedorento, e está quebrado, e a merenda é ruim, é muito sujo e as salas de aulas estão com muito buraco. Final de carta.
} 
(1d) Querida diretora, Querida diretora meu nome e A5 estol reclamando do banheiro que esta muito cusjo e fedorento e a sala de aula esta rabiscada.

Sem mais

A5 (Produção Final)

Ao observarmos as cartas de $\mathrm{A} 5$, notamos um significativo progresso em relação à estrutura composicional do gênero carta de reclamação.

Na produção inicial, exemplo (1a), A5 escreveu sua carta utilizando uma estrutura que se distancia completamente da estrutura do gênero foco da pesquisa. Esta apresenta um título e, em seguida, as reclamações, as quais estão organizadas em forma de tópicos. Elementos prototípicos da estrutura do gênero carta, como a abertura do evento (local, data, vocativo e saudação), o corpo da carta e o encerramento do evento não aparecem na produção inicial de A5.

No entanto, notamos que, na segunda carta, exemplo (1b), alguns elementos do gênero já se fazem presentes, tais como a data e o destinatário. Percebemos também que as reclamações já não estão em tópicos, mas em forma de parágrafo.

Na terceira produção, exemplo (1c), embora ainda não apresente todos os elementos composicionais do gênero, percebemos um significativo progresso em relação à utilização dos elementos prototípicos do gênero carta de reclamação. Notamos a presença do vocativo, além do desenvolvimento de três parágrafos com objetivos diferentes, ou seja, no primeiro parágrafo temos a apresentação do redator, no segundo temos a reclamação propriamente dita e no terceiro temos um breve agradecimento e uma sugestão. A carta finaliza com a assinatura.

Por fim, na última produção, temos todos os elementos estruturais do gênero carta de reclamação, ou seja, a carta apresenta a abertura do evento (data, local, vocativo), o corpo da carta, embora de maneira breve, e o encerramento do evento (despedida e assinatura).

Vale ressaltar a disposição tipográfica da última carta. Notamos um aprimoramento na última produção da disposição tipográfica prototípica do gênero carta de reclamação, além de uma melhora na ortografia das palavras. Todavia, embora apresente apenas um parágrafo, percebemos que o propósito comunicativo da carta foi atingido.

Ao observarmos as cartas dos demais alunos que participaram das quatro produções, perceberemos um progresso significativo na apropriação do gênero carta de reclamação, semelhantemente ao progresso presente nas produções de A5. Vejamos as produções iniciais e finais, nos seguintes exemplos (2a), (2b), (3a) e (3b):

(2a) Eu gosto da sala de informática, quadra para brincar, sala de vedo, creio, passeio, merenda, educação, aprender a escrever, feriado, igreja, casa do pai, casa da minha avó, meu amigo, invenções.

Ass: $A 1$

Eu não gosto das salas quentes e da direção. (Produção Inicial)

Fortaleza, 01 de outubro de 2012

Querida diretora,

Meu nome é A1 tenho 10 anos sou do $4^{\circ}$ ano da escola Maria Bezerra Quevedo. 
Queria fazer uma reclamação, o banheiro esta quebrado, riscado e com defeito.

$N a$ salas de aula a parede estão riscadas, quebradas e os ventiladores estão quebrados.

Sem mais

\section{Al (Produção Final)}

(3a)

Fortaleza 03/09/2012

Senhora diretora

Eu não gosto

1. Brigas entre colegas - por que tei que ter mais respeito

2. Sala é quente - por que tei três vetilador e pouca persiana

3. Banheiro das meninas - por que não tei espelio não tei saboneite e não tei descasga

4. Fardamento - por que paresi fardamento de trabalho o sapato é feio é pra muda a cor.

5. Merenda-por que asvezeis é ruim e é bom como a sopa de peixe

6. Cadeiras - por que são riscadas quebradas inferrujadas

7. Água-por que é quente e sulja

8. Bebedor - por que só tei dois e é muito queite

9. Relógio - por que não tei na sala só da geiti

Ass: A3 (Produção Inicial)

Fortaleza, 01 de outubro de 2012

\section{Prezada diretora,}

Meu nome é As teio 12 anos e faço $4^{\circ}$ ano B e esstudo na escola Maria Bezerra Quevedo. Eu estou rreclamando do banheiro porque não tem descarga e só tem uma Luis que presta e rreclama também da sala de aula que é muito queite e zuadenta.

Si a siora fize um banheiro bonito e limpo a geite vai fica feliz e si a sala de aula fosse boua a geite vai estuda melho

Sem mais

\section{$A s($ Produção Final)}

Análise e discussão dos exemplos (2a), (2b), (3a) e (3b) nos levam à seguinte constatação: os alunos que participaram das atividades estruturadas na sequência didática apresentaram um significativo progresso na apropriação dos elementos estruturais prototípicos do gênero carta de reclamação.

Avaliamos que os resultados observados em relação à quantidade e à adequação dos elementos estruturais do gênero do gênero em questão confirmam nossa hipótese de que após o desenvolvimento da SD verificarse-ia, nas produções dos sujeitos da pesquisa, um considerável progresso no conhecimento dos elementos estruturais do gênero carta de reclamação.

Os dados evidenciam que as dificuldades relativas ao domínio da estrutura composicional do gênero em estudo estão relacionadas, principalmente, à orientação didática dos trabalhos pedagógicos em sala de aula, ou seja, a falta de orientação para este fim proporciona o desconhecimento dos alunos em relação aos elementos composicionais do gênero carta de reclamação.

Com isso, comprovamos que após a realização da SD houve a apropriação do gênero carta de reclamação. Isso reforça o postulado de Schneuwly \& Dolz (2004) de que é preciso criar contextos de produção precisos para que noções e técnicas não espontaneamente acessíveis sejam adquiridas pelos alunos.

Verificamos, por fim, que o trabalho com gêneros textuais e sequências didáticas revelou-se instrumento útil para a construção de uma escrita voltada aos interesses dos aprendizes e possibilitou em seu papel Forum linguistic., Florianópolis, v.11, n.4, p.385-402, out./dez.2014. 
didático e social: de um gênero a aprender, embora permanę̧a gênero para comunicar (SCHNEUWLY; DOLZ, 2004, p. 81).

Tendo por escopo os propósitos da nossa pesquisa, a sequência didática foi desenvolvida por meio de atividades que conduzissem os alunos ao desenvolvimento do discurso argumentativo escrito. Para tanto, a proposta das quatro cartas, produzidas ao longo da SD, era que os alunos escrevessem cartas de reclamação para diretora da escola, apontando os problemas existentes na instituição e argumentando o porquê da necessidade da resolução de tais problemas. Assim, o tema das cartas de reclamação produzidas foram os problemas existentes na escola.

Para analisarmos o desenvolvimento do tema nas produções dos participantes, observaremos a questão do engajamento ou não do aluno ao tema proposto.

No exemplo A1, a seguir, poderíamos dizer que a estratégia de argumentação do aluno seria apontar o que gosta, sinalizando o que funciona na escola para chamar a atenção para o que não funciona e, por conseguinte, do que não gosta:

(4) Eu gosto da sala de informática, quadra para brincar, sala de vedo, creio, passeio, merenda, educação, aprender a escrever, feriado, igreja, casa do pai, casa da minha avó, meu amigo, invenções.

Ass: A1

(5)

Fortaleza 03 de setembro de 2012

Senhora Diretora

Briga entre colegas

Banheiros

Salas muito quentes

Fardamento

Merenda rui

A menina grita muito

Monitores

Ass: A4

Verificamos, ao contrapormos os textos produzidos pelos participantes das atividades da sequência didática, como os alunos superam parte dos problemas, relacionados ao desenvolvimento do tema, constatados na produção inicial. Vejamos a progressão de A4, nos exemplos (5a), (5b), (5c) e (5d):

(5a)

Senhora Diretora

Briga entre colegas

Banheiros

Salas muito quentes

Fardamento

Merenda rui

A menina grita muito

Monitores

Ass: A4 (Produção Inicial)
Fortaleza 03 de setembro de 2012
Fortaleza 19 de setembro de 2012 


\section{Querida diretora}

Um meu none e A4, e eu quero reclama da sala de aula por que a sala e quenti e a meninas grita.

É eu queria que a escola se muito legal na hora do recreio, e a merenda e rui.

Sem mais nada,

$$
A 4\left(\mathbf{2}^{\mathrm{a}}\right. \text { Produção) }
$$

Fortaleza, 24 de setembro de 2012

Prezada diretora,

O meu nome é A4, e eu quero reclama du banheiro do colégio estão rabiscado não tem espelho e a maioria dos vasos sanitários estão quebrados as luz não funcionam e não tem papel higiênico no banheiro dos meninos.

A senhora já faz muitas coisas por essa escola como educação física que está legal. Se a senhora vaz um banheiro do menino fica já menho como a escola do governo.

Sem mais

$$
\left.A 4 \text { ( } 3^{\text {a }} \text { Produção }\right)
$$

Fortaleza, 01 de outubro de 2012

\section{Senhora diretora,}

O meu nome é At e eu quiria reclama do banheiro, porque o banheiro tam muito sujo é o banheiro tam ser epenho e a privada tam suja.

E a sala de aula é muito cedi é a menina gritato e a sala de aula presisa de arcondicionado porque a sala fais muito calo é presisa de relógio pra os aluno ver a hora.

Sem mais,

\section{A4 (Produção Final)}

Ao analisarmos as produções de A4, percebemos uma considerável diferença entre estas. Embora a primeira produção apresente os elementos composicionais da estrutura do gênero carta, tais como a abertura do evento (local, data e vocativo), o corpo da carta e o encerramento do evento, com presença apenas da assinatura, notamos que no corpo da carta não há um desenvolvimento dialogal do objeto do discurso. $\mathrm{O}$ aluno apresenta suas ideias em forma de tópicos, sem fazer menção de que seu texto se trata de uma reclamação. Se o leitor da carta compartilhar da intenção do escritor, ou seja, se for de conhecimento do leitor de que se trata de uma carta de reclamação, provavelmente este identificará quais reclamações o escritor está fazendo, contudo, sem argumentos que possam gerar o convencimento ou adesão do leitor. No entanto, se esta intenção não for compartilhada com o leitor, provavelmente o propósito comunicativo não será estabelecido, haja vista não conter marcas linguísticas de reclamação e/ou argumentação no corpo do texto.

Não obstante, após a sequência de quatorze aulas, objetivando o desenvolvimento do discurso argumentativo escrito em cartas de reclamação, percebemos um aprimoramento significativo na produção do A4. A estrutura composicional do gênero carta de reclamação, que se apresentou de modo parcial na primeira produção, encontra-se mais elaborada na segunda, terceira e quarta, assim como percebemos um relativo aprimoramento do desenvolvimento do tema nas duas últimas produções.

Na última produção, o escritor da carta do exemplo (5) apresentou suas reclamações oferecendo argumentos que fundamentam tais reclamações, por exemplo, "eu quiria reclama do banheiro, porque o banheiro tam muito sujo é o banheiro tam ser epenho e a privada tam suja” (exemplo 5d). Assim, mesmo que o objetivo da carta não 
seja compartilhado previamente com o leitor, o propósito comunicativo será estabelecido, uma vez que o conteúdo proposicional apresenta-se de forma mais clara.

Apesar do significativo progresso na escrita da carta de reclamação, no exemplo (5), notamos que o aluno ainda não consegue sistematizar uma reclamação seguida de reivindicação, que seria o ritual típico das cartas de reclamação. Tal objetivo, certamente, será alvo para o desenvolvimento de outra sequência didática.

Os alunos fazem reclamações pertinentes ao cotidiano escolar e reconhecem na figura do diretor o poder de resolução dos problemas, conforme podemos evidenciar no fragmento a seguir:

A senhora já faz muitas coisas por essa escola como educação fisica que está legal. Se a senhora vaz um banheiro do menino fica já menho como a escola do governo. (A4- $\mathbf{3}^{\mathbf{a}}$ produção)

Em suma, constatamos que os alunos participantes da sequência didática apresentaram progresso no desenvolvimento do tema das cartas de reclamação e que a progressão temática manifesta por meio da reclamação seguida de reivindicação também foi aprimorada pelos redatores e, por fim, verificou-se, nas últimas produções dos sujeitos, uma adequação das reclamações feitas nas cartas produzidas.

\section{CONSIDERAÇÕES FINAIS}

O dia a dia está cada vez mais cheio de situações que corroboram para a massificação do pensamento não crítico e da formação do cidadão enquadrado socialmente nos interesses políticos dominantes. No entanto, chamamos a atenção para a real necessidade da formação do indivíduo politicamente consciente de seus direitos e deveres sociais. Acreditamos, contudo, que um dos caminhos para a formação crítica do cidadão se dará por meio do desenvolvimento do discurso argumentativo desde a tenra idade, ou seja, através do ensino sistemático, os indivíduos serão capazes de organizar seu discurso, oral e escrito, tendo em vista a defesa de valores e posicionamentos ideológicos.

Todavia, ao observarmos a atual estrutura de ensino básico, perceberemos que o texto argumentativo não compõe a estrutura curricular do processo de ensino e aprendizagem do fundamental I. Apenas nos anos finais do Ensino Fundamental podemos ver uma iniciação ao estudo da argumentação e somente no Ensino Médio a argumentação passa a ter obrigatoriedade na estrutura curricular de ensino.

Destarte, neste estudo, partimos do pressuposto de que a argumentação encontra-se marcada nas escolhas linguísticas e que os sentidos dos enunciados indicam a direção da continuação do diálogo, orientando o interlocutor a certo tipo de conclusão (DUCROT, 1989). Assim, sob o ponto de vista da argumentação na língua, em que o encadeamento argumentativo está ligado à estrutura linguística dos enunciados, avaliamos que o desenvolvimento deste trabalho nos proporcionou um maior entendimento sobre como conduzir as atividades de produção textual nas salas de aula, considerando as expectativas dos alunos.

Certamente, não só pela evolução gradual na aprendizagem dos conteúdos a que os alunos foram expostos, o trabalho de produção de textos escritos, organizados por meio de sequências didáticas, proporcionou aos alunos a oportunidade de utilizar reflexivamente a língua escrita. Assim, corroborando com a afirmação de Leitão (2011, p. 43), nosso estudo aponta que "o engajamento na argumentação cria no indivíduo um tipo de experiência metacognitiva (pensar sobre o próprio pensamento) que lhe possibilita tomar consciência e agir (fundamentar, avaliar, reafirmar, reformular) sobre seu próprio pensamento”.

Com isso, comprovamos nossa hipótese de que após o desenvolvimento da SD verificar-se-ia, nas produções dos sujeitos da pesquisa, um considerável progresso no conhecimento dos elementos estruturais do gênero carta de reclamação.

Constatamos ainda que os alunos participantes da sequência didática apresentaram progresso no desenvolvimento do tema das cartas de reclamação. Os dados evidenciaram que o grande número de alunos que apresentaram fuga total ao tema na produção inicial conseguiu desenvolver a temática nas duas últimas produções. Os resultados também apontam que a progressão temática manifesta por meio da reclamação 
seguida de reivindicação também foi aprimorada pelos redatores e, por fim, verificou-se, na última produção dos sujeitos, uma adequação das reclamações feitas nas cartas produzidas.

Nosso estudo comprovou, portanto, que após a realização da SD, houve o desenvolvimento do discurso argumentativo nas cartas de reclamação analisadas. Isso reforça o postulado de que é preciso criar contextos de produção precisos para que noções e técnicas não espontaneamente acessíveis sejam adquiridas pelos alunos (SCHNEUWLY; DOLZ, 2004).

Destarte, acreditamos que quanto mais cedo o estudante tiver contato, em sala de aula, com o ensino sistemático da argumentação, teremos mais probabilidade de formar bons produtores de textos argumentativos.

\section{REFERÊNCIAS}

BAKHTIN, M. Os gêneros do discurso. In: BAKHTIN, M. Estética da criação verbal. Tradução Maria Ermantina Galvão G. Pereira. São Paulo: Martins Fontes, 2003 [1953]. p. 261-270.

BALOCCO, A. E. A perspectiva discursivo-semiótica de Guther Kress: o gênero como um recurso representacional. In: MEURER, J. L.; BONINI, A.; MOTTA-ROTH, B. (Org.) Gêneros: teorias, métodos, debates. São Paulo: Parábola Editorial, 2005 p.65-80.

BARTON, D.; HALL, N. (Org.). Letter writing as a social practice. Amsterdã/Filadélfia: John Benjamins, 2000.

BARBOSA, J.P. Carta de solicitação e carta de reclamação. São Paulo: FTD, 2005.

BAZERMAN, C. Cartas e a base social de gêneros diferenciados. In: DIONÍSIO, A.P. \& HOFFNAGEL, J.C. (Org.). Gêneros textuais, tipificação e interação. São Paulo: Cortez Editora, 2011. p. 89-107.

BOISSINOT, A. Les textes argumentatifs. Toulouse: Bertrand-Lacoste, 1992.

BRONKART, J. P; SCHNEUWLY. La didactique du francais langue maternelle: l'emergence d'une utopie indispensable. Revue Education et Recherche. Genève. n.1, p. 08-25, 1991.

DUCROT, O. Argumentação e Topoï argumentativo. In: GUIMARAES, Eduardo (Org.). História e sentido na linguagem. Campinas, SP: Pontes Editores, 1989. p. 13-38.

GOMES, A. L. S. F. Argumentação escrita e as crianças: um estudo sobre a capacidade de julgamento de texto argumentativo. 2002. 84f. Dissertação (Mestrado em Psicologia) - Instituto de Psicologia, Universidade Federal do Rio de Janeiro, Rio de Janeiro, 2002.

JUBRAN, C. C. C. A. S. et al. Organização tópica da conversação. In: ILARI, R. (Org.). Gramática do português falado. V II. Campinas/SP: UNICAMP, São Paulo: FAPESP, 1992. p. 341-378.

KOCH, I.GV. Desvendando os segredos do texto. São Paulo: Contexto, 2003.

LEITÃO, S. O lugar da argumentação na construção do conhecimento em sala de aula. In: LEITÃO, S.; DAMIANOVIC, M. C. (Org.). Argumentação na escola: o conhecimento em construção. Campinas, São Paulo: Pontes Editora, 2011. p. 13-45.

LIMA, M. C. de C. Desenvolvimento da escrita argumentativa: os efeitos de um ensino sistemático da argumentação para alunos da $5^{\text {a }}$ série do ensino fundamental. 2006. 88f. Dissertação (Mestrado em Educação) - Faculdade de Educação, Universidade Federal do Paraná, Curitiba, 2006.

MARCUSCHI, L. A. Gêneros textuais emergentes no contexto da tecnologia digital. In: MARCUSCHI, L. A.; XAVIER, A. C. (Orgs.). Hipertexto e gêneros digitais: novas formas de construção de sentido. São Paulo: Cortez, 2010. p. 15-80. 
MARCUSCHI, L. A. Apresentação. In: BEZERMAN, C. Gêneros textuais, tipificação e interação. DIONÍSIO, A. P.; HOFFNAGEL, J. C. (Org.). São Paulo: Cortez, 2011, p. 5-10.

MELO, B. O. R. de. Letramento e apropriação do gênero textual carta de reclamação no contexto da educação de jovens e adultos. 2009. 2899f. Tese (Doutorado em Linguística) - Programa de Pós-Graduação em Linguística, Universidade Federal do Ceará, Fortaleza, 2009.

MORAIS, A.G.; ALBUQUERQUE, E. B.C. Alfabetização e letramento: o que são? Como se relacionam? Como "alfabetizar letrando"? In: ALBUQUERQUE, E. B. C.; LEAL, T. F. Alfabetização de jovens e adultos em uma perspectiva de letramento. Belo Horizonte, Autêntica, 2004. p. 40-60.

SCHNEUWLY, B; DOLZ, J. Os gêneros escolares - das práticas de linguagem aos objetos de ensino. In: Gêneros orais e escritos na escola. Tradução e organização de Roxane Rojo e Glaís Sales Cordeiro. Campinas: Mercado das Letras, 2004. p. 21-39.

. Gêneros e tipos de discurso: considerações psicológicas e ontológicas. In: Gêneros orais e escritos na escola. Tradução e organização de Roxane Rojo e Glaís Sales Cordeiro. Campinas: Mercado das Letras, 2004. p. 21-40.

SILVA, J. Q. G. Um estudo sobre carta pessoal: das práticas comunicativas aos indícios de interatividade. 2004. 208f. Tese (Doutorado em Educação) - Faculdade de Educação, Universidade Federal de Minas Gerais, Belo Horizonte, 2002. 